\title{
DIREITO E DESIGUALDADES: SÍNDROME DA ALIENAÇÃO PARENTAL E O ABORTO PATERNO
}

\author{
LAW AND INEQUALITY: ALIENATION SYNDROME AND FATHER \\ (PARENTAL) ABORTION
}

${ }^{1}$ Catharina Orbage De Britto Taquary

\section{RESUMO}

O aborto paterno é um novo termo que caracteriza a falta da figura paterna na vida do menor e que normalmente leva à Síndrome da Alienação Parental. A problemática deste artigo está pautada no ideal de guarda do menor e da dificuldade de aceitação pelos genitores do fim da sociedade conjugal. Dentre as hipóteses estão a SAP e o aborto paterno. Os objetivos visados têm o intuito de fomentar a constante avaliação psicológica do núcleo familiar para que haja a superação do momento de ruptura da estrutura familiar e da constante presença dos genitores na vida do menor.

Palavras-chave: Direito e desigualdades, Síndrome de alienação parental, Aborto paterno

\begin{abstract}
Paternal abortion is a new term that characterizes a father figure in the life of the minor and that usually leads to the Parental Alienation Syndrome. The issue of this article is guided in the ideal of custody of the child and the difficulty of acceptance by parents in the end of the conjugal society. Among the hypotheses are PAS and parental abortion. The targeted objectives are intended to promote the constant psychological evaluation of the nuclear family so there is overcoming the moment of breakdown of the family structure and the constant presence of parents in child's life.
\end{abstract}

Keywords: Law and inequality, Parental alienation syndrome, Paternal abortion

\footnotetext{
${ }^{1}$ Doutoranda em Direito pelo Centro Universitário de Brasília - UniCEUB, Brasília, DF, (Brasil). Advogada.Email: catharinaorbage@yahoo.com.br.
} 


\section{INTRODUÇÃO}

O Século XXI é marcado pelo individualismo. A estrutura social e, consequentemente, a estrutura familiar deixa de ser clássica e tradicional em sua formação e passam a sofrer rupturas.

Essas rupturas geralmente são formadas pelo divórcio, o qual termina a sociedade conjugal entre o casal. A liberdade e a facilidade de se pedir e ter o divórcio concedido trouxe para os casais o sossego de poder errar em suas escolhas e concertá-las ou modificá-las através do fim da sociedade conjugal.

Contudo, por outro lado, a liberdade e facilidade em se obter o divórcio trouxeram outro aspecto, qual seja a guarda dos filhos. A guarda dos filhos passou a ser unilateral com permissão de visitas, ou ainda, compartilhada.

Teoricamente, a ideia da guarda compartilhada ou até mesmo a unilateral com visitas demonstram certa tranqüilidade na criação dos filhos. Porém, na prática é observado que os filhos normalmente são cuidados somente por um dos genitores.

Isso significa que não necessariamente somente um dos genitores providencie ou arque com a pensão alimentícia ou quaisquer outros custos necessários para a vida do menor. Vai muito além, educar, cuidar, criar um filho não parte somente de valores financeiros, mas de valores morais, éticos e sociais, os quais devem ser ensinados por ambos os genitores.

É na criação que está a problemática deste artigo. Tem-se o intuito de demonstrar o novo fenômeno ou talvez a nova nomenclatura do problema mais antigo que a estrutura familiar continua enfrentando, qual seja: o abandono familiar.

É evidente que quando se trata de abandono familiar pode-se tratar do abandono materno ou paterno. Entretanto, neste artigo o objetivo é tratar do abandono paterno. A nomenclatura que aqui será utilizada para tratar este fenômeno será o aborto paterrno.

O aborto é comumente tratado quando pessoas do sexo feminino, mulheres, resolver terminar a gravidez antes do nascimento do feto. Sabe-se que no Brasil, o aborto é proibido, salvo nos artigos previstos pelo Código Penal Brasileiro em vigor. 
Já o aborto paterno está intimamente ligado a afetividade que é recusada ao menor por diversos fatores, principalmente, o abandono afetivo. Este abandono afetivo pode estar relacionado tanto à mãe da criança quanto ao menor, ou ainda, a ambos. Abandono este que não necessariamente deve acontecer na gravidez, mas após o nascimento e/ou desenvolvimento da criança.

É com base neste instituto, a afetividade da estrutura familiar que este artigo irá desenvolver uma pesquisa e análise crítica sobre a guarda unilateral, a síndrome de alienação parental e o aborto paterno.

\section{A RUPTURA DA ESTRUTURA FAMILIAR}

A modernidade traz diversas implicações para a estrutura familiar. A modernidade pode ser dividida em duas: a primeira é baseada nos Estados-nacionais, com relações estritamente entendidas no sentido territorial; e na segunda modernidade a sociedade precisa a responder a todas as demandas simultaneamente (BECK, 2010, p. 368).

Os problemas atuais são resultantes, mas não antecipados, da modernização industrial, baseada no Estado-nação. E, a partir disso, surgem "auto ameaças“ que não podem ser controladas (BECK, 2010, p. 368).

A antiga ideia de controlabilidade, segurança e certeza, tão fundamental à primeira modernidade, entra em colapso. Ou seja, um novo tipo de capitalismo, de sociedade, de economia e de vida pessoal surge na segunda modernidade, criando a necessidade de um novo quadro de referência (BECK, 2010, p. 368).

Na sociedade do risco mundial, o mundo compartilha das mesmas mudanças básicas (não apenas o ocidente): há uma pluralização de modernidades, sob diferentes percepções culturais (BECK, 2010, p. 368).

Há aspectos positivos (democracia, multiculturalismo, tolerância) e negativos (crise do Estado, flexibilização do trabalho, desemprego, terrorismo).Os riscos são globais e estão intimamente ligados a decisões técnicas, administrativas e políticas. Os riscos também pressupõem decisões. Estas são tomadas com base em normas fixas de cálculo. São tais normas que a sociedade do risco mundial está tornando inválidas (BECK, 2010, p. 368).

Os cálculos de segurança privada não cobrem as crises econômicas, catástrofes, mudança de clima, entre outros fatores. Isto significa que as mais controversas tecnologias 
não estão asseguradas. De modo que os riscos políticos, ecológicos, individuais escapam mais dos mecanismos de proteção e controle (BECK, 2010, p. 368).

Ao mesmo tempo em que a sociedade passa a ter consciência do risco, comporta-se de acordo com o modelo da "velha" sociedade industrial. O processo de modernização é alheio aos perigos que causa. Tais perigos latentes levam ao questionamento e transformam os fundamentos da sociedade industrial. Há duas fases nesse processo:

1) As consequências e auto ameaças são produzidas sistematicamente, sem serem publicamente tematizadas. A sociedade industrial potencializa e legitima os riscos produzidos;

2) Quando os riscos dominam os debates políticos e os conflitos públicos, as instituições convertem-se em focos de produção e legitimação de "perigos controláveis“.

Quatro pilares são rompidos quando os riscos passam a ser globais e nãocontroláveis:

1) Os danos não são mais delimitáveis: são globais e irreparáveis

2) Os cuidados preventivos dos piores acidentes ficam excluídos

3) O "acidente" perde suas delimitações: passa a ser um acontecimento com começo, mas "sem final".

4) Assim, suprimem-se os estandartes de normalidade - necessários para a medida e cálculo do risco.

É neste sentido que surge a modernidade reflexiva. É uma auto confrontação com os "efeitos colaterais latentes" da sociedade de risco, em que tais efeitos não podem ser mensurados nem assimilados pelas instituições sociais.

Há uma crise no consenso do progresso e na abstração dos efeitos indesejáveis. É através da abstração (negação) da sociedade do risco que esta surge e se realiza. Reflexividade é, portanto, a transição reflexiva da sociedade industrial à sociedade de risco.

Os Conflitos de danos se sobrepõem aos de distribuição. Passa a se questionar as "atribuições" de cada ator. As pretensões de controle, centradas na técnica, chocam-se com a concatenação das carências de segurança, escândalos encobertos e as "quase catástrofes". Há um potencial político que reside no colapso da racionalidade técnico-científica e das garantias institucionais de segurança (BECK, 2010, p. 368). 
Os riscos menores tecnicamente manejáveis são regulados até os detalhes, enquanto os grandes perigos são "legalizados" pelo sistema. Novos conhecimentos podem transformar, de um dia para outro, normalidade em perigo (BECK, 2010, p. 368).

O progresso da ciência refuta suas próprias asseverações iniciais a propósito da segurança. Todos os perigos (genéticos, químicos, ecológicos, etc.) são produzidos por decisões. Isso indica um fracasso dos sistemas sociais (BECK, 2010, p. 368).

Altera-se a relação da moderna sociedade industrial com a natureza; assim como as representações e a consciência de segurança dos problemas e perigos gerados e/ a ação política. Em função das turbulências, há uma decomposição e desencantamento da base do sentido coletivo (fé no progresso, questões de classe) ligadas a valores do século XX (BECK, 2010, p. 368).

Oportunidades, ambivalências e perigos antes relacionados à comunidade local, à família, aos deteriorados grupos e classes sociais, devem ser percebidos pelo indivíduo, num ambiente de riscos sociais distribuídos. As decisões políticas não dominam a incerteza ou a possibilidade de destruição e autoameaça (BECK, 2010, p. 368).

As grandes organizações industriais do futuro operam "sem proteção" ou seguro. A reflexividade e a incalculabilidade se propagam por todos os domínios da sociedade. A sociedade do risco tende a ser autocrítica, dividindo a sociedade e mesmo o indivíduo (conflito interno), em suas escolhas (BECK, 2010, p. 368).

É a partir da sociedade de risco que há a ruptura da estrutura familiar. É a partir da modificação da modernidade para a modernidade reflexiva que a família deixa de ser instituto rígido, estável e típico de Estado.

\section{SÍNDROME DE ALIENAÇÃO PARENTAL - SAP}

A síndrome da alienação parental está prevista pela Lei n. 12.318/2010, considerando alienação parental o ato que interfere na formação psicológica da criança ou do adolescente promovida ou induzida por um dos genitores, pelos avós ou por aqueles que tenham a criança ou adolescente sob a sua autoridade, guarda ou vigilância para que repudie o genitor ou que prejudique o estabelecimento ou a continuidade do vínculo afetivo (BRASIL, LEI N. $12.318 / 2010)$. 
A título de exemplos da alienação parental, além daqueles atos declarados pelo Magistrado ou por perícia, praticados diretamente ou com auxilio de terceiros destacam-se os seguintes (BRASIL, LEI N. 12.318/2010).

I - realizar campanha de desqualificação da conduta do genitor no exercício da paternidade ou maternidade;

II - dificultar o exercício da autoridade parental;

III - dificultar contato de criança ou adolescente com genitor;

IV - dificultar o exercício do direito regulamentado de convivência familiar;

$\mathrm{V}$ - omitir deliberadamente a genitor informações pessoais relevantes sobre a criança ou adolescente, inclusive escolares, médicas e alterações de endereço;

VI - apresentar falsa denúncia contra genitor, contra familiares deste ou contra avós, para obstar ou dificultar a convivência deles com a criança ou adolescente;

VII - mudar o domicílio para local distante, sem justificativa, visando a dificultar a convivência da criança ou adolescente com o outro genitor, com familiares deste ou com avós.

Cerca de um em cada dois casamentos nos Estados Unidos termina em divórcio, que afeta cerca de um milhão de crianças por ano. Cerca de $10 \%$ destes divórcios envolvem guardas litigiosas. Algumas crianças são ou tornam-se emocionalmente distante de um ou ambos os pais durante este processo (http://www.leadershipcouncil.org/1/pas/faq.htm.).

A causa desse estranhamento não pode ser determinada sem uma profunda compreensão da história e da dinâmica da família. A pesquisa mostrou que as questões subjacentes ao apego dos pais ou estranhamento são complexas e não se prestam a respostas fáceis. No entanto, alguns avaliadores de custódia da criança confiam em teorias simplistas "ciência lixo" para explicar o comportamento da criança e recomendam soluções do tipo "one size fits all" para forçar a criança a dividir o seu amor igualmente entre os pais (http://www.leadershipcouncil.org/1/pas/faq.htm.).

Síndrome de Alienação Parental (SAP) é uma teoria. Esta teoria sem sofisticação, pseudocientífica explica o distanciamento de uma criança de um dos pais ou alegações de abuso nas mãos de um dos pais, culpando o outro (http://www.leadershipcouncil.org/1/pas/faq.htm.). 
A teoria, desenvolvida pelo Richard A. Gardner, MD, retrata o pai preferencial (geralmente a mãe sob SAP) como um "alienante" o mal que é praticamente o único responsável por transformar uma criança vulnerável contra a sua mãe distante (geralmente o pai sob SAP) (http://www.leadershipcouncil.org/1/pas/faq.htm.).

A solução simplista é a de separar a criança do pai que eles preferem e colocá-los com o pai que rejeita ou relata como ter abusado deles. Apesar do fato de que muitos dos pressupostos subjacentes da teoria da SAP têm sido repetidamente refutada cientificamente (http://www.leadershipcouncil.org/1/pas/faq.htm).

Gardner acredita que os juízes devem fazer backup de conclusões dos terapeutas treinados em SAP com toda a força da lei e impor multas, perda permanente de custódia, e penas de prisão para os pais que não cumprirem (http://www.leadershipcouncil.org/1/pas/faq.htm.).

Apesar de alguns profissionais avaliadores da saúde mental e de guarda da criança, advogados e juízes têm sido rápidos em aceitar e admitir a SAP como prova nessas disputas, não houve nenhuma evidência empírica ou clínica consistente que SAP é uma síndrome válida ou que o chamado "alienante do "o comportamento é a causa real do comportamento da criança alienada para o pai de destino (WALKER, 2005, p. 47-74).

Para evitar os efeitos devastadores da Alienação Parental (AP), deve-se começar por reconhecer os sintomas da AP. Nota-se que muitos dos sintomas ou comportamentos focam no pai. Quando a criança apresenta ódio e vilipendia o pai-alvo, em seguida, a condição se torna síndrome de alienação parental (DARNALL, http://www.parentalalienation.org/articles/symptoms-parental-alienation.html., p. 07-34).

Dar às crianças opções quando eles não têm escolha sobre as visitas. Permitindo que a criança decida por si mesma sobre visitar quando a ordem judicial diz que não há escolha configura conflito para a criança (DARNALL, http://www.parentalalienation.org/articles/symptoms-parental-alienation.html., p. 07-34).

A criança geralmente culpa o pai não-residencial por não ser capaz de decidir se deve ou não visitar. O pai está agora vitimado independentemente do que acontece; não ser capaz de ver seus filhos ou se não vê-los, as crianças estão com raiva (DARNALL, http://www.parentalalienation.org/articles/symptoms-parental-alienation.html., p. 07-34).

Dizer "tudo" ao filho sobre a relação conjugal ou razões para o divórcio é alienante. O pai normalmente argumenta que eles estão "apenas querendo ser honesto" com seus filhos. Esta prática é destrutiva e dolorosa para a criança. O motivo do genitor alienante é para a 
criança a pensar menos do outro progenitor (DARNALL, http://www.parentalalienation.org/articles/symptoms-parental-alienation.html., p. 07-34).

Recusando-se a reconhecer que as crianças têm a propriedade e podem querer transportar suas posses entre residências. Resistir ou se recusar a cooperar, não permitindo que o outro acesso do pai à escola ou registros médicos e horários de atividades extracurriculares. Quando um dos genitores culpa o outro progenitor por problemas financeiros, quebrando-se a família, as mudanças no estilo de vida, ou ter uma namorada / namorado, etc. são atitudes típicas da síndrome de alienação parental (DARNALL, http://www.parentalalienation.org/articles/symptoms-parental-alienation.html., p. 07-34).

Recusar-se a ser flexível com o horário de visitação, a fim de responder às necessidades da criança. O genitor alienante também pode agendar as crianças em muitas atividades que o outro progenitor nunca é dado o tempo para visitar. Claro que, quando os protestos pai-alvo, eles são descritos como não se importar e egoísta (DARNALL, http://www.parentalalienation.org/articles/symptoms-parental-alienation.html., p. 07-34).

Pedindo à criança para escolher um dos pais em detrimento de outro pai faz com que o sofrimento considerável criança. Normalmente, eles não querem rejeitar um dos genitores, mas em vez disso querem evitar o problema. A criança, não o pai, deve iniciar qualquer sugestão de mudança de residência (DARNALL, http://www.parentalalienation.org/articles/symptoms-parental-alienation.html., p. 07-34).

Quando um pai usa uma criança para espionar ou secretamente recolher informações para uso próprio do pai, a criança recebe uma mensagem prejudicial que avilta o pai vitimado. Os pais que criam tentações que interferem com a visitação da criança (DARNALL, http://www.parentalalienation.org/articles/symptoms-parental-alienation.html., p. 07-34).

Um genitor sugerindo ou reagindo com mágoa ou tristeza ao seu filho ao ter um bom tempo com o outro pai fará com que a criança se retraia e não se comunique. Eles freqüentemente se sentem culpados ou conflitosos sem saber que a ele é permitido se divertir com seu outro pai (DARNALL, http://www.parentalalienation.org/articles/symptomsparental-alienation.html., p. 07-34).

Um dos genitores quando pedem à criança informações sobre a vida pessoal do outro genitor faz com que a tensão da criança aumente em face do conflito. As crianças que não são alienados querem ser leais a ambos os pais (DARNALL, http://www.parentalalienation.org/articles/symptoms-parental-alienation.html., p. 07-34). 


\section{ABORTO PATERNO}

O termo aborto paterno a ausência da figura masculina na vida do menor. Trata do abandono afetivo do genitor paterno. Esse abandono pode ocorrer na gravidez, no nascimento e/ou no crescimento da criança e do adolescente. $\mathrm{O}$ aborto paterno também pode ocorrer quando o genitor não reconhece o filho ou, ainda, quando foge do compromisso da paternidade.

Atualmente no Brasil existem cerca de 5,5 milhões de crianças que não têm em sua filiação o genitor paterno. Esse dado é fornecido pelo Conselho Nacional de Justiça. São inúmeras crianças com o pai desconhecido (BRASIL, CONSELHO NACIONAL DE JUSTIÇA, 2016).

Os Estados que lideram o ranking é Rio de Janeiro, São Paulo e Roraima. Trata-se de um evidente caso de irresponsabilidade social. O direito ao nome do pai na certidão de nascimento é um direito à personalidade inerente a identidade de toda criança (BRASIL, CONSELHO NACIONAL DE JUSTIÇA, 2016).

É cultural no Brasil que o homem tenha certa dificuldade em assumir uma família, seja formal ou informal, vide o instituto da União Estável, o qual surgiu exatamente na tentativa de proteger as mulheres, mães que são abandonadas por seus parceiros durante ou após a gravidez.

São raros os casos em que os pais solteiros assumem seus filhos e proporcionam o reconhecimento e o afeto necessário a toda criança e adolescente. Não é por acaso que culturalmente a ideia de filho está sempre associada à figura da mãe. É de praxe ensinar a suas filhas e netas que ao engravidarem os problemas serão exclusivamente delas, do sexo feminino.

Contudo, apesar da lenta evolução e amadurecimento, bem como do empoderamento das mulheres pode-se falar em aborto paterno. Quando o genitor paterno aborta, ele abre mão de forma consciente de ser um pai presente e afetivo para com seu filho.

O aborto paterno geralmente está associado à ideia de relacionamentos que chegam ao final antes do nascimento da prole e os genitores paternos simplesmente abandonam suas ex-companheiras ou ex-esposas na tentativa de seguir com sua vida como se fosse possível apagar tudo aquilo vivido, inclusive a vida do nascituro, da criança ou do adolescente. 
Nem toda situação que ocorre durante um divórcio é um produto racional, bem planejado e cuidadosamente deliberado de avaliação. Em situações de violência doméstica ou de discussão em frente das crianças, as partes devem separar o mais rapidamente possível para proteger o bem-estar emocional das crianças e proteger contra danos uns aos outros, a propriedade e os direitos parentais (http://www.attorneys.com/divorce/what-constitutesspousal-or-marital-abandonment/, p. 1).

Em situações menos voláteis, os genitores que enfrentam um divórcio devem ter em devida conta vários fatores antes de tomar a decisão de sair de casa. Os fatores incluem considerações financeiras, as considerações dos pais e abandono (http://www.attorneys.com/divorce/what-constitutes-spousal-or-marital-abandonment/, p. 1)

O abandono é uma relação dinâmica que ocorre quando um adulto ou criança voluntariamente nega ou ignora as principais responsabilidades (papel) que alguém os espera a cumprir, como obrigações parentais ou conjugais. (GERLACH, 2015, p. 01 - 43).

Optam por terminar um relacionamento existente com outra pessoa, apesar de seu parceiro não querer isso. É, claramente, uma experiência traumática quando o abandonado depende da outra pessoa seja financeiramente ou psicologicamente, como em um período gestacional ou um adulto incapaz. (GERLACH, 2015, p. $01-43$ ).

O abandono pode ser psicológico (indiferença, apatia, "frieza", falta de intimidade); e/ou física. O divórcio psicológico ocorre quando um ou ambos os companheiros que coabitam abandonam o outro, inclusive abandonando suas responsabilidades e relações de primazia. A discussão de abandono geralmente se concentra em um adulto sair ou desistir. (GERLACH, 2015, p. $01-43$ ).

Há uma distinção importante devida a causa da condenação moral e legal tradicional de abandono dos pais ou do cônjuge. Os pais feridos que são abandonados (não são "emocionalmente disponíveis") para os seus filhos e não pode ajudá-los psicologicamente. (GERLACH, 2015, p. $01-43$ ).

Dentre os impactos de um abandono em uma criança por nascer indesejada estão o ressentimento e maus tratos um ou ambos os pais são duros, sem resposta, e / ou ausentes em face de criança pequena; divórcio dos pais, e o pai ausente escolhem pouco ou nenhum contato com seus filhos ou ex, ou ainda, quando uma criança torna-se deficientes mentais. É comum o genitor escolher um trabalho que exige que ele fique longe de casa por semanas ou meses em um momento. (GERLACH, 2015, p. 01 - 43). 
São impactos sobre o sistema familiar que demonstram plenamente as causas e os impactos em diferentes níveis em um adulto ou em abandono de crianças, ver a família afetada em forma extensa como um sistema dinâmico. (GERLACH, 2015, p. 01 - 43).

O abandono físico ou psicológico muda os papéis de um sistema familiar, papéis, rituais e tradições, subsistemas e interações sociais em formas complexas. Estas alterações simultâneas causam ansiedade temporária ou em longo prazo até que os membros da família se adaptam a eles e se estabilizam. (GERLACH, 2015, p. 01 - 43).

Eles podem diminuir o nível de nutrição da família ("funcionalidade"), e, geralmente, causam na maioria ou em todos os familiares perdas significativas que precisam são lamentadas ao longo do tempo. (GERLACH, 2015, p. 01 - 43).

Os efeitos na infância e em longo prazo, da ausência excessiva dos pais pode variar de moderada a grave, dependendo da idade da criança, o sexo, a sua ligação com o adulto ausente (fraca>forte), e seu nível de nutrição da família alargada (baixo>alto).

A experiência comum sugere que, quando as crianças estão fisicamente abandonadas por um pai - ou se o genitor principal é emocionalmente indisponível (não tem vínculo) - as crianças estão gravemente feridas. (GERLACH, 2015, p. 01 - 43).

Sua mágoa é uma mistura de choque, se o abandono foi inesperado e / ou explosiva; e de confusão. Muitas questões mentais e as incertezas sobre o abandono e o que isso significa levam a vergonha (baixa auto-estima) - sentir-se amado e indigno, mesmo que outros adultos dêem carinho genuíno e atenção; e, possivelmente, o sentimento incluía culpa (irracionalmente) que fez algo de ruim ou errado que causou o abandono; e / ou temores de ligação com alguns ou todos os adultos / homens / mulheres. (GERLACH, 2015, p. 01 - 43).

A sensação de abandono permanece inclusive quando precisa de outros profissionais como o caso de profissionais de saúde, com a possível sensação de que eles também podem abandoná-los. (GERLACH, 2015, p. 01 - 43).

Em longo prazo a tristeza continua sendo involuntária, e mais tarde, perde-se a esperança e fantasia de reuniões familiares, ou seja, da estrutura familiar. A criança é criada em um ambiente avesso a estrutura familiar, mesmo que de forma inconscientemente, o que pode levar a um luto inacabado na idade adulta como uma depressão periódica ou crônica. (GERLACH, 2015, p. $01-43$ ).

Combinados, esses fatores de estresse podem causar misturas de desconfiança significativas, ressentimentos e raivas que muitas vezes levam até a idade adulta. Quando 
combinado com o abuso de um genitor com negligência, esses estresses podem inibir a capacidade da criança de ligação (Transtorno de Apego Reativo, ou RAD). (GERLACH, 2015, p. $01-43)$.

Outro impacto que podem ocorrer e não se tornam evidentes até a idade adulta é o efeito da ausência dos pais no sentido de identidade de gênero de uma criança. As meninas precisam de afirmação e valorização da sua feminilidade de uma figura paterna. Precisam de modelagem materna consistente "como ser feminino" e deleite na filha como uma menina especial, amada. (GERLACH, 2015, p. $01-43$ ).

Os meninos precisam observar como um pai (um homem) se comporta, e aprender como gerenciar e apreciar a sua masculinidade - especialmente como se relacionar com mulheres e outros homens. (GERLACH, 2015, p. $01-43$ ).

Porém, se as dores do abandono são intensas o suficiente, uma criança abandonada pode desenvolver dormência emocional e / ou "amnésia" seletiva (repressão) para se protegerem de recordar e re-experimentar os seus traumas e perdas de abandono. Um ou mais dos seus eu interiores na personalidade pode vivenciar o passado, e ainda temer a dor lancinante da re-abandono. (GERLACH, 2015, p. 01 - 43).

Estes efeitos são muitas vezes ampliados por causa dos pais que abandonam e geralmente os sinais são: (a) baixa referência familiar (disfuncional) da infância, e dos genitores e ancestrais; (b) feridas significativas e inconscientes. (GERLACH, 2015, p. 01 43).

As crianças menores podem também desenvolver reações avessas a outros membros da família para o abandono. Como por exemplo: caso alguns membros da família tratem com desprezo e difamem o adulto que abandonou. O dilema está na obrigatoriedade de escolha entre a lealdade ao seu pai ausente e outros parentes. Quando mais velhos, as crianças menos feridas podem tem tendência de se separarem e não se alinharem a qualquer lado de ambos os genitores, sem culpa excessiva ou ansiedade. (GERLACH, 2015, p. 01 - 43).

O abandono de crianças ocorre quando pai ou tutor de uma criança deliberadamente retém apoio emocional, físico e financeiro, sem ter em conta para a segurança e o bem-estar do menor (LEGAL DICTIONARY, 2016, p. 1).

Isso pode incluir o abandono físico, como deixar uma criança em algum lugar sem a intenção de voltar para ele, ou pode incluir falha ao fornecer supervisão física, apoio emocional, e outras necessidades da vida para uma criança que vive em casa. Os menores podem, em casos extremos, ser considerados abandonados por seu trabalho ou os pais de 
outra maneira ausente. Muitos comportamentos parentais levam a acusações de abandono de crianças, incluindo (LEGAL DICTIONARY, 2016, p. 1):

- Deixar uma criança em uma porta, em uma lata de lixo, ou na beira da estrada;

- Estar ausente do lar por um período de tempo suficientemente longo para criar risco substancial de dano para a criança entregue em casa;

- Deixar uma criança com outra pessoa sem prever o apoio da criança, e sem comunicação significativa com a criança por um período determinado por lei, geralmente três meses;

- Deixar de manter a visita regular com uma criança;

- Fazendo apenas esforços simbólicos para apoiar e comunicar com uma criança;

- Recusar-se, ou não estar disposto, para fornecer supervisão, cuidados e apoio para uma criança;

- Deixar de participar de um plano de parentalidade ou programa destinado a reunir o pai com a criança;

- Não responder a notificação oficial da criança no processo de proteção ou a guarda dos filhos.

"Hoje à noite, cerca de 40 por cento das crianças no mundo ocidental vão dormir em casas em que seus pais não vivem." Antes que eles atinjam a idade de dezoito anos, mais de metade das crianças dos Estados Unidos da América estão propensos a gastar pelo menos uma parte significativa de sua infância vivendo além de seus pais. É o maior índice de abando voluntário na história do país (BLANKENHORN, 2015, p. 07 - 43).

.A ausência do pai é a tendência demográfica mais nociva desta geração. É a principal causa do declínio da criança e bem-estar de adultos na sociedade. É também o motor de condução dos problemas sociais mais urgentes (BLANKENHORN, 2015, p. 07 - 43).

Desde o final da Segunda Guerra Mundial, tem havido um interesse crescente por parte dos governos e comentaristas sociais nos efeitos do pai ausente no desenvolvimento das pessoas dentro da unidade familiar restante (BLANKENHORN, 2015, p. 07 - 43). 
Curiosamente, estudos apontam que os efeitos dos pais emocionalmente indisponíveis eram quase idênticos às em que o pai era fisicamente ausente. Afeta, inclusive, as diferenças físicas (isto é, o desenvolvimento acelerado na puberdade de crianças criadas sem pai presente) através de muitas e variadas questões sociais e fisiológicas. Em referência aos indivíduos da população em geral criados em um ambiente de pai ausente demonstram que (BLANKENHORN, 2015, p. 07 - 43):

1. Cinco vezes a taxa média de suicídio;

2. Aumento dramático das taxas de depressão e ansiedade;

3. Diminuição dos níveis de educação e aumento das taxas de abandono;

4. Níveis de rendimento médio consistentemente mais baixos;

5. Aumento das taxas de divórcio e as questões de relacionamento;

6. Aumento substancial nas taxas de abuso de substâncias; e,

7. Aumento nos problemas sociais e mentais de comportamento.

Como medir um sentimento de abandono e traição? Como medir o sentimento de não pertencer e de ser diferente? A ausência do pai de muitas maneiras rouba o direito de nascença; leva das estruturas internas inerentes e naturais. Estas são as estruturas que dependem todos os indivíduos todos os dias em todos os aspectos de nossas vidas, seja em relacionamentos, nível de felicidade, na saúde, no comportamento, na prosperidade ou nível de sucesso. Se essas estruturas inerentes estão em falta ou não são permitidas para desenvolver plenamente, então esse indivíduo realmente nunca tem a chance de realizar o potencial completo (BLANKENHORN, 2015, p. 07 - 43).

\section{POSSIBILIDADE DE ESCOLHA DO MENOR}

A prática de ato de alienação parental fere o direito fundamental da criança ou do adolescente de "convivência familiar saudável, prejudica a realização de afeto nas relações com genitor e com o grupo familiar, constitui abuso moral contra a criança ou o adolescente e descumprimento dos deveres inerentes à autoridade parental ou decorrentes de tutela ou guarda" (BRASIL, LEI N. 12.318/2010). 
A alienação parental é mais comum do que é frequentemente assumida: Fidler e Bala (KRUK, 2010, p. 16 - 43) relatam tanto um aumento da incidência e aumento descobertos judiciais de alienação parental; eles relatam estimativas de alienação parental em 11-15\% dos divórcios envolvendo crianças; Bernet et al (2010, p. 76 - 187) estimam que cerca de $1 \%$ das crianças e adolescentes na América do Norte a experiência de alienação parental (FIDLER, BALA, 2010, p. 10 - 47).

Há agora um consenso acadêmico que a alienação grave é abusiva para crianças (FIDLER, BALA, 2010, p. 10 - 47)., e é uma forma largamente ignorada de abuso infantil (Bernet et al, 2010), como praticantes de bem-estar infantil e divórcio são muitas vezes desconhecem ou minimizam a sua extensão.

Conforme relatado por filhos adultos de divórcio, as táticas dos pais alienantes são equivalentes a maus tratos psicológicos extremos a crianças, incluindo rejeição, aterrorizando, isolamento, corrompimento ou aproveitamento, e negando a capacidade de resposta emocional (BAKER, 2010, p. 16 - 35).

Para a criança, a alienação parental é uma condição mental grave, com base em uma falsa crença de que o genitor alienado é um pai perigoso e indigno. Os efeitos graves da alienação parental sobre as crianças estão bem documentadas; baixa auto-estima e auto-ódio falta de confiança, depressão e abuso de substâncias e outros tipos de dependência são generalizados, como as crianças perdem a capacidade de dar e aceitar o amor de um pai (KRUK, 2010, p. 16-43).

Auto-ódio é particularmente preocupante entre as crianças afetadas. Como as crianças internalizam o ódio voltado para o genitor alienado, são levados a crer que o genitor alienado não ama ou quer que eles, e a experiência de culpa grave relacionado a trair o genitor alienado.

Sua depressão está enraizada em sentimentos de não ser amado por um de seus pais e de separação do que o pai, ao ser negada a oportunidade de lamentar a perda de um dos pais, ou mesmo falar sobre o pai.

Crianças alienadas normalmente têm relações conflituosas ou distantes com o genitor alienante também, e estão em alto risco de tornar-se alienado de seus próprios filhos; Baker relata que metade dos entrevistados em seu estudo dos filhos adultos que tinham experimentado alienação como as crianças estavam separadas de seus próprios filhos (KRUK, 2010, p. 16-43). 
Cada criança tem um direito fundamental e necessidade de uma relação sem ameaças e amorosa com ambos os pais, e para ser negado esse direito por um dos pais, sem justificação suficiente, como abuso ou negligência, é em si uma forma de abuso infantil. Uma vez que é a riança que está sendo violada por comportamentos alienantes de um genitor, é a criança que está sendo alienado do outro progenitor (KRUK, 2010, p. 16 - 43).

As crianças que tenham sido submetidos à separação forçada de um de seus pais, na ausência de abuso, incluindo os casos de alienação parental, são altamente sujeitas a stress pós-traumático, e os esforços de reunificação nestes casos deve proceder com cuidado e sensibilidade (a pesquisa mostrou que muitas crianças alienadas podem transformar rapidamente de recusa ou firmemente resistindo ao genitor rejeitado para ser capaz de mostrar e receber amor de que o pai, seguido por uma mudança igualmente rápida volta para a posição alienada quando voltar na órbita do genitor alienante (KRUK, 2010, p. 16 - 43).

As crianças alienadas parecem tem um desejo secreto de alguém para chamar seu blefe, obrigando-os a se reconectar com os pais que dizem odiar. Enquanto os desejos expressos das crianças relativas ao contato dos pais em guarda impugnada, deve ser considerada, mas não devem ser determinante, especialmente em casos suspeitos de alienação (KRUK, 2010, p. $16-43$ ).

O ódio não é uma emoção que vem naturalmente a uma criança; ele tem que ser ensinado. Um pai que iria ensinar uma criança a odiar ou temer o outro progenitor representa um perigo grave e persistente para a saúde mental e emocional dessa criança. crianças alienadas não são menos danificados do que outras crianças vítimas de conflito extremo, como crianças-soldado e outras crianças raptadas, que se identificam com seus algozes para evitar a dor e manter um relacionamento com eles, no entanto abusiva essa relação pode ser (KRUK, 2010, p. $16-43$ ).

\section{CONCLUSÃO}

Após a pesquisa e análise crítica desenvolvida neste artigo, pode-se afirmar que a problemática presente na síndrome de alienação parental é o abandono afetivo. Este abandono afetivo surge quando a mãe da criança deixa de receber o afeto do pai, seja por fim do relacionamento, seja por abandono material ou, ainda, pelo não reconhecimento jurídico de paternidade.

A genitora detém a guarda unilateral do menor e passa a desenvolver rancor pelo pai da criança justamente pelo tratamento que lhe foi dado por ele. Neste artigo não foi 
intencionado discutir o mérito de nenhum dos genitores, nem seus sentimentos particulares pela questão em si.

Contudo, a ideia é que sempre prevaleça o bem-estar físico e psicológico do menor. O aborto paterno é tratado aqui justamente com o objetivo de demonstrar que as sociedades latinoamericanas ainda sofrem visivelmente com sentimentos machistas, nos quais transformam a estrutura familiar com algo extremamente descartável.

O pai, genitor, abandona a mãe do menor já no período gestacional e, a partir disso, se torna cada vez mais distante do seu próprio filho. Quando em outros casos nem se quer se faz presente e, simplesmente, abandona a genitora grávida.

Não cabe a este artigo discutir a legislação existente, uma vez que a vigente é de fato suficiente para tratar o problema de pensão alimentícia. Porém, não se pode obrigar aos genitores e ao menor a relação afetiva. Ter sentimentos pelos genitores e pelo filho não é algo que se possa ser obrigado.

Podem, contudo, esses sentimentos serem trabalhados dentro da sociedade de modo que seja menos masculinizada a ideia de que filho é da mulher. Deve-se desenvolver culturalmente a ideia de que família não precisa morar na mesma casa, nem serem casados ou viver em união estável, mas que podem nutrir o sentimento de carinho, amor e pertença a uma estrutura familiar.

Estrutura esta que não precisa ser desamparada pelo homem, porque ele acredita ser menos másculo por trocar fraldas ou dar banho em seus filhos, mas pelo sentimento que ele próprio nutriu em saber que ali está a sua prole. E que a genitora, sendo ou não sua cônjuge ou companheira, faz parte dessa herança que necessita de afeto e participação constante. Evidente, que um pacto não existe de forma unilateral e a genitora deve ter claro que a estrutura familiar pode ser diferenciada e presente de forma simultânea.

\section{REFERÊNCIAS}

BAKER, A. (2010). “Adult Recall Of Parental Alienation In A Community Sample: Prevalence And Associations With Psychological Maltreatment.” Journal of Divorce and Remarriage, 51, 16-35.

BECK, Ulrich. Sociedade de Risco: Rumo a outra Modernidade. São Paulo: Ed. 34; 2010.

BERNET, W. et al (2010). "Parental alienation and the DSM V." American Journal of Family Therapy, 38, 76-187. 
BLANKENHORN, David. The 9 Devastating Effects Of The Absent Father. Disponível em: https://thefathercode.com/the-9-devastating-effects-of-the-absent-father/. Acesso em: 20/03/2016.

BRASIL. LEI N. 12.318/2010. Disponível em: http://www.planalto.gov.br/ccivil_03/_ato2007-2010/2010/lei/112318.htm. Acesso em: $16 / 03 / 2016$.

CONSELHO NACIONAL DE JUSTIÇA. Disponível em: http://www.cnj.jus.br/. Acesso em: $16 . / 03 / 2016$

DARNALL, Douglas. Symptoms of Parental Alienational. Disponível em: http://www.parentalalienation.org/articles/symptoms-parental-alienation.html. Acesso em: 16/03/2016.

FIDLER, B. and BALA, N. (2010). "Children Resisting Postseparation Contact With A Parent: Concepts, Controversies, And Conundrums." Family Court Review, 48 (1), 10-47. GERLACH, Peter K. Perspective on Parental Abandonment: Causes, Effects, and Options. Disponível em: http://sfhelp.org/gwc/abandon.htm. Acesso em: 20/03/2016.

. What is Parental Alienation Syndrome (PAS)? Disponível em: http://www.leadershipcouncil.org/1/pas/faq.htm. Acesso em: 16/03/2016.

- What Constitutes Spousal or Marital Abandonment? Disponível em: http://www.attorneys.com/divorce/what-constitutes-spousal-or-marital-abandonment/. Acesso em: 20/03/2016.

KRUK, Edward. The Impact of Parental Alienation on Children: Undermining Loving Parent-Child Relationships as Child Maltreatment. Disponível em: https://www.psychologytoday.com/blog/co-parenting-after-divorce/201304/the-impactparental-alienation-children. Acesso em: 16/03/2016.

LEGAL DICTIONARY. Child Abandonment. Disponível em: http://legaldictionary.net/child-abandonment/. Acesso em: 20/03/2016.

WALKeR, L. E., Brantley, K. L., \& Rigsbee, J. A. (2005). A Critical Analysis of Parental Alienation Syndrome and Its Admissibility in the Family Court. Journal of Child Custody, 1(2), 47-74. 